\title{
REPRESENTAÇÃO \\ SOCIAL DE PROFESSORES/AS EM TEXTOS JORNALÍSTICOS DE REVISTAS SEMANAIS DE INFORMAÇÃO
}

\author{
REPRESENTACIÓN SOCIAL DE PROFESORES (AS) EN TEXTOS PERIODÍSTICOS DE \\ REVISTAS SEMANALES DE INFORMACIÓN
}

\author{
SOCIAL REPRESENTATION OF TEACHERS IN JOURNALISTIC TEXTS OF WEEKLY NEWS \\ MAGAZINE
}

\author{
Amanda Oliveira Rechetnicou* \\ Universidade de Brasília \\ Sostenes Lima** \\ Universidade Estadual de Goiás
}

\begin{abstract}
RESUMO: Neste trabalho, temos como objetivo interpretar e discutir a representação social construída para professores/as em textos jornalísticos de revistas semanais de informação. Buscamos estabelecer uma relação entre o conceito de representação nos estudos linguísticos e sociodiscursivos - da Análise Crítica de Gêneros (ACG), da Análise de Discurso Crítica (ADC) e da Linguística Sistêmico-Funcional (LSF) - e nos estudos de Psicologia Social, a partir da Teoria das Representações Sociais (TRS). Como resultado, encontramos no corpus constituído por reportagens, artigos e entrevistas das revistas semanais IstoÉ e Veja formas de representação docente marcadas por efeitos ideológicos que, em geral, desfavorecem a imagem e as atividades do professor.
\end{abstract}

\footnotetext{
* Doutoranda em Linguística pela Universidade de Brasília (PPGL/UnB), com bolsa CAPES, e mestra em Educação, Linguagem e Tecnologias pela Universidade Estadual de Goiás (PPG-IELT/UEG). E-mail: amanda_yea@hotmail.com.

** Doutor em Linguística pela Universidade de Brasília. Docente do Programa de Pós-graduação em Educação, Linguagem e Tecnologias (PPG-IELT) da Universidade Estadualde Goiás (UEG).E-mail: limasostenes@gmail.com.
} 
PALAVRAS-CHAVE: Representação social de professores/as. Gêneros jornalísticos. Revista semanal de informação.

RESUMEN: Este trabajo tiene como objetivo interpretar y discutir la representación social de profesores (as) en textos periodísticos de revistas semanales de información. Se busca establecer una relación entre el concepto de representación desarrollado en los estudios lingüísticos y sociodiscursivos (en las áreas de Análisis Crítico de Géneros - ACD, de Análisis Crítico del Discurso - ACD y de la Lingüística Sistémico-Funcional - LSF) y el concepto de representación social desarrollado en los estudios de Psicología Social, a partir de la Teoría de las Representaciones Sociales (TRS). Los resultados encontrados en el corpus constituido por reportajes, artículos y entrevistas de las revistas semanales IstoÉ y Veja indican que existen formas de representación docente marcadas por efectos ideológicos que, en general, desfavorecen la imagen y las actividades del (de la) profesor (a).

PALABRAS CLAVE: Representación social de profesores (as). Géneros periodísticos. Revista semanal de información.

ABSTRACT: In this work, we aim to interpret and discuss the social representation of teachers in journalistic articles of weekly news magazines. We seek to establish a relationship between representation in linguistic and sociodiscursive studies - from Critical Genre Analysis (CGA), Critical Discourse Analysis (CDA) and Systemic-Functional Linguistics (SFL) - and in the studies of Social Psychology - from the Theory of Social Representations (TSR). We used a corpus consisting of reports, articles and interviews of the weekly magazines IstoÉ and Veja. Results show the potential and ideological effects of the exclusion of teachers in the texts, as well as of the constructed forms of representation that, in general, disfavor the image and activities of teachers.

KEYWORDS: Social representation of teachers. Journalistic genres. Weekly news magazine.

\section{INTRODUÇÃO}

A representação negativa de professores/as nas grandes mídias tem sido constantemente abordada em estudos na área da Educação, da Comunicação e também da Linguagem (LAWN, 2001; FERREIRA, 2012; ALVES-MAZZOTI, 2007, 2008; BRAGA, CAMPOS, 2016; LEITE, 2013). Esses estudos apontam, de modo geral, que a imagem do/a docente está associada, no discurso jornalístico, a um sentido que tende a reproduzir a ideia de que os problemas da educação são reflexos da má formação e do despreparo dos/as professores/as.

Ferreira (2012), em sua pesquisa sobre o modo como notícias de grandes jornais brasileiros constroem representações para o/a professor/a, afirma que os textos jornalísticos costumam distorcer as bandeiras legítimas e históricas dos movimentos docentes, como o reconhecimento de seu papel profissional, a valorização da carreira e o aumento de salário. Segundo a autora, é possível perceber com frequência a predominância de um movimento discursivo que desqualifica o/a professor/a, a partir do argumento pró-qualidade, ao responsabilizá-lo/a inteiramente pela má qualidade do sistema de ensino brasileiro.

Em outra perspectiva, ao fazer um estudo da imagem do/a professor/a na mídia segundo a Teoria das Representações Sociais (TRS), Braga e Campos (2016) mostram que, quando a educação é tratada como mercadoria em textos jornalísticos, os/as professores/as são representados como meros/as operacionalizadores/as de desempenho e não como participantes ativos do processo de ensino e aprendizagem.

Este trabalho, por conseguinte, visa contribuir com as discussões promovidas nesse campo de estudos. Temos como foco interpretar aspectos e efeitos potencialmente ideológicos da representação de professores/as em gêneros jornalísticos de revistas semanais de informação.

Entendemos a representação como uma estratégia que tem papel significativo na construção e reprodução de diferentes modos de identificar atores sociais, principalmente quando está atrelada a interesses e posicionamentos que estabelecem e sustentam desigualdades sociais. Além disso, consideramos que os diversos gêneros jornalísticos que circulam nas práticas sociais desempenham papel fundamental na mediação e legitimação de representações e identificações específicas que, no caso deste estudo, centram-se nos atores sociais docentes, em especial, da educação básica no Brasil. 
A seguir, apresentamos primeiramente as abordagens teórico-metodológicas que fundamentam o trabalho. Buscamos estabelecer uma relação entre a representação nos estudos linguísticos e sociodiscursivos - da Análise Crítica de Gêneros (ACG), da Análise de Discurso Crítica (ADC) e da Linguística Sistêmico-Funcional (LSF) - e na perspectiva da Psicologia Social, a partir da Teoria das Representações Sociais (TRS). Em seguida, explicitamos os caminhos metodológicos tomados para a análise de reportagens, artigos e entrevistas das revistas semanais IstoÉ e Veja. A seção que se segue apresenta a análise e interpretação dos textos em foco. Por fim, evidenciamos algumas (in)conclusões e reflexões sobre a análise e os resultados obtidos.

\section{A REPRESENTAÇÃO EM ESTUDOS SOCIODISCURSIVOS}

Com base na Análise Crítica de Gêneros (ACG), na Análise de Discurso Crítica (ADC) e na Linguística Sistêmico-Funcional (LSF), buscamos compreender os diversos aspectos que envolvem a representação em gêneros jornalísticos.

A ACG consiste em uma proposta de estudo de gênero em relação ao contexto, com enfoque em problemas sociais, principalmente no que se refere ao papel de gêneros discursivos em lutas hegemônicas. Trata-se de uma perspectiva transdisciplinar, por se constituir a partir de diferentes abordagens que têm como foco o estudo de gêneros e discursos, dentre elas, a Análise Sociorretórica de Gêneros (ASG), a ADC e a LSF.

A análise de gêneros numa perspectiva crítica se importa com os sentidos ideológicos e seus efeitos nas práticas sociais. Ao explanar uma proposta de "[...] estudos de gêneros como ciência social crítica, especialmente no que tange ao estudo dos gêneros jornalísticos [...]", Bonini (2012, p. 2) descreve a ACG como uma perspectiva ocupada em investigar o papel de gêneros na construção e legitimação de sentidos a serviço do poder (THOMPSON, 2011).

A abordagem da representação na ADC considera a importância e o papel de gêneros discursivos na legitimação de representações específicas construídas para eventos e atores sociais. A representação, ao ser produzida e mediada a partir de discursos e gêneros específicos, como os que compõem o campo jornalístico, pode servir de modo potencial a "[...] interesses particulares projetados para estabelecer e sustentar relações de dominação [...]" (RAMALHO; RESENDE, 2011, p. 26).

Na perspectiva da ADC, Fairclough (2003) explica que o discurso figura de três modos nas práticas sociais: modo de ação e interação social, modo de representação e modo de identificação. Esses modos estão ligados a elementos das ordens e significados do discurso. As ordens do discurso são compreendidas como redes de práticas sociais no aspecto linguístico, que se constituem dos elementos: gêneros, discursos ${ }^{1}$ e estilos, sendo que os gêneros estão associados ao significado acional, os discursos ao significado representacional, e os estilos ao significado identificacional.

Gêneros, discursos e estilos são combinados a partir de uma proposta de análise interdiscursiva e dialética, em que discursos são interpretados em gêneros e apontados em estilos, enquanto ações e identidades (gêneros e estilos) são representadas em discursos (FAIRCLOUGH, 2003). Desse modo, os três aspectos do significado são organizados numa complexa relação dialética, dentro da qual podem ser misturados, articulados e tecidos de maneiras particulares e, assim, desencadear (ou não) mudanças sociais.

\footnotetext{
${ }^{1} \mathrm{Na}$ ADC, discurso (no singular) refere-se ao seu significado mais abstrato, de linguagem como forma de prática social. Enquanto discursos (geralmente no plural), num sentido mais concreto, conceitua modos particulares de representar aspectos do mundo (FAIRCLOUGH, 2003; RAMALHO, RESENDE, 2011).
} 
Portanto, representação para a ADC está associada ao modo como os discursos representam diferentes perspectivas do mundo relações e processos materiais de nossa experiência, bem como processos mentais, pensamentos, sentimentos e crenças. As representações, nesse sentido, dizem respeito ao modo como as pessoas representam e se relacionam com o mundo, e isso depende de posições, identidades e relações sociais.

Um mesmo aspecto do mundo pode ser representado de diferentes maneiras, dependendo de posicionamentos e interesses específicos de determinados grupos sociais. Como afirma Fairclough (2001), quando se representa algo, se escolhe fazer de um modo em vez de outro. Por meio de discursos particulares, ideologias são legitimadas para a manutenção de relações assimétricas de poder. A busca por hegemonia de determinado grupo social implica a busca pela universalização de "sentidos particulares" (RAMALHO; RESENDE, 2011, p. 52).

Fairclough (2003) afirma que a análise de gênero dá uma importante contribuição para a pesquisa sobre relações entre mudança tecnológica, mediação, mudança econômica e amplas mudanças sociais. Nesse sentido, a análise de gêneros contribui tanto para mostrar como as novas tecnologias constituem novos gêneros dentro de processos econômicos, políticos, socioculturais, como para demonstrar como cadeias de gêneros são tecidas na sociedade de informação.

As transformações sociais podem ser vistas como mudanças nas formas de ação e interação (FAIRCLOUGH, 2003). Isso implica processos de hibridização de gêneros e mudanças sociais, que podem estar ligadas à operação de sentidos a serviço do poder. Como Ramalho e Resende (2011, p. 66) afirmam, "[...] hibridismos de gêneros podem servir para fins ideológicos. Isso acontece quando a mistura de gêneros se associa a questões relacionadas a poder e ideologia”.

O modo como pessoas articulam discursos, como se expressam e atuam no mundo por meio de gêneros é importante para a compreensão da maneira como elas estruturam identidades. Os discursos constroem formas de ser no mundo, constroem significados identificacionais para o eu e o outro, por assim dizer.

Questões de identidade têm sido amplamente discutidas devido às transformações recentes na vida social. Isso porque identidades de grupos particulares estão ligadas a lutas baseadas em interesses específicos na manutenção ou mudança das relações desiguais de poder. Assim como gêneros e discursos, a construção de modos particulares de identificação de atores sociais é uma estratégia discursiva nas lutas ideológicas por hegemonia.

Para a análise da representação, Fairclough (2003) propõe uma série de categorias ligadas ao significado representacional, dentre elas, a categoria da representação de atores sociais segundo o modelo teórico-analítico da representação social de van Leeuwen (1997), que é fundamentado na LSF, conforme discutiremos na subseção a seguir.

\subsection{A REPRESENTAÇ̃̃O DE ATORES SOCIAIS}

A proposta teórico-analítica da representação de atores sociais, desenvolvida por van Leeuwen (1997, p. 169), tem como base a LSF e apresenta um "[...] inventário semântico social dos modos pelos quais os atores sociais podem ser representados [...]”. O quadro a seguir contém uma síntese das categorias referentes à representação de atores sociais: 


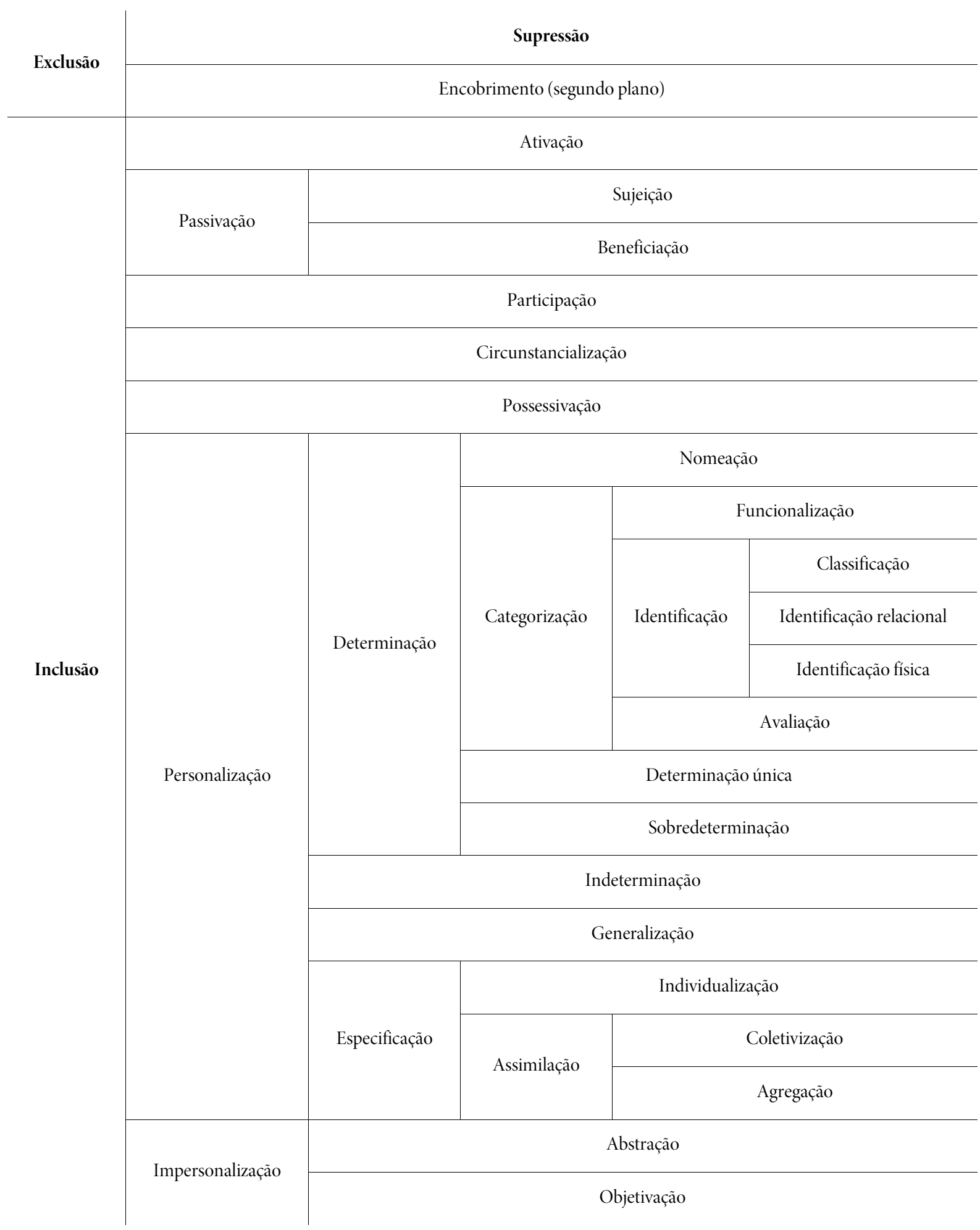

Quadro 1: Síntese das categorias de representação de atores sociais

Fonte: Quadro adaptado de Resende e Ramalho (2006), com base em van Leeuwen (1997)

O primeiro aspecto da representação considerado por van Leeuwen (1997) é a presença ou ausência de atores sociais no texto. Segundo o autor, "[...] as representações incluem ou excluem atores sociais para servir a seus interesses e propósitos em relação aos leitores a quem se dirigem" (LEEUWEN, 1997, p. 180). A exclusão ocorre por supressão de menções a atores sociais ou por encobrimento, quando são colocados em segundo plano. Já a inclusão considera os diferentes modos pelos quais atores sociais podem ser representados. As escolhas semânticas referentes à representação podem ter implicações ideológicas importantes para a compreensão de como se constroem identificações específicas em gêneros jornalísticos. 
Neste estudo, algumas categorias foram consideradas básicas por sua recorrência na representação de docentes. A exclusão por supressão e por colocação em segundo plano aponta para sentidos ideologicamente relevantes, enquanto a inclusão ocorre, de modo recorrente, a partir da personalização, ou seja, quando o/a produtor/a do texto utiliza de pronomes pessoais ou possessivos, nomes próprios ou outros substantivos para a construção da representação. Alguns componentes comuns em gêneros jornalísticos são: a nomeação, a categorização, a generalização e a especificação.

Segundo Van Leeuwen (1997), as narrativas da imprensa dão preferência pela nomeação e categorização dos atores sociais porque assim eles se tornam pontos de identificação para o/a leitor/a. A categorização ocorre, em grande parte, por funcionalização, classificação, identificação relacional e avaliação. Os atores sociais podem ser representados, nesse sentido, pela função e/ou profissão, por seus papéis, relações ou classes sociais, bem como por meio de julgamentos e atributos avaliativos. A personalização também pode acontecer por meio da generalização (referência genérica) e da especificação, em que os atores sociais são representados de modo individual ou por coletivização (referência específica).

Essas categorias contribuem para a interpretação das escolhas lexicais usadas na representação de atores sociais e, mais especificamente, de professores/as em gêneros jornalísticos. Elas podem apontar crenças, valores, ideologias que perpassam a representação social e a produção de textos da esfera midiática.

\section{A REPRESENTAÇÃO EM ESTUDOS DA TEORIA DAS REPRESENTAÇÕES SOCIAIS}

Na Psicologia Social, a noção de representação social tem origem nos estudos de Serge Moscovici, com a publicação La psychanalyse, son image et son public: étude sur la représentation sociale de la psychanalyse, em $1961^{2}$. Nessa perspectiva, o estudo das representações sociais investiga a constituição e o funcionamento dos sistemas de referência que usamos para classificar pessoas e grupos sociais, bem como interpretar os acontecimentos da realidade cotidiana e as relações das pessoas com as dimensões da realidade.

As representações sociais são, nesse sentido, como afirma Moscovici (2010), teorias coletivas sobre o real, repletas de implicações baseadas em valores, conceitos e ideias compartilhadas de modo consensual pelos grupos sociais. Não são apenas opiniões sobre algo/alguém ou imagens de algo/alguém, mas sistemas que possuem uma lógica e linguagem específicas.

Segundo Moscovici (2010), pessoas e grupos criam representações por meio da comunicação (da linguagem) e da interação social. É no interior das relações sociais que nascem novas representações, as quais ocupam o lugar das velhas a partir da criação de sentidos consensuais que visam abarcar a complexidade dos eventos e das ações sociais, facilitar a comunicação e orientar as práticas do cotidiano.

Nessa abordagem, a representação é compreendida a partir de sua natureza psicológica e social. Na análise de natureza psicológica, Moscovici (1978) propõe a investigação de dois processos: a objetivação e a ancoragem. A objetivação diz respeito ao processo que transforma conceitos e ideias em esquemas ou imagens concretas, enquanto a ancoragem tem como foco a rede de significações que envolve os objetos, eventos e atores sociais representados. A análise psicológica, a partir desses dois processos, é importante para a Teoria das Representações Sociais (TRS) por permitir a compreensão de como o funcionamento do sistema cognitivo interfere no social e como o social interfere na elaboração cognitiva, objetivo primordial da TRS, segundo aponta Jodelet (2001).

${ }^{2}$ Em português, a obra foi publicada em 1978, sob o título Representação social da psicanálise. 
$\mathrm{Na}$ análise de natureza social, Moscovici (1978) propõe investigar as proposições, os valores e avaliações que fazem parte da construção das representações sociais, considerando aspectos culturais, interacionais e sociais. Esses elementos que envolvem a representação se organizam de modo a constituir diferentes universos de opinião, universos de ideias e valores que criam uma imagem concreta - uma representação - da realidade social.

Seguindo a trilha de Moscovici, Jodelet (2001) define as representações sociais como modalidades de conhecimento prático, uma forma específica de conhecimento que orienta a comunicação, a compreensão do contexto social e a construção de uma ideia de realidade comum, ou seja, uma forma de pensamento social. As representações, segundo a autora, manifestam-se como elementos cognitivos - conceitos, imagens, teorias - mas não se reduzem a tais elementos, por serem socialmente constituídas e compartilhadas. Portanto, podem ser consideradas essencialmente como fenômenos sociais que, apesar de serem acessados por meio do conteúdo cognitivo, devem ser entendidos a partir de seu contexto de produção e difusão.

Um fator importante do ponto de vista social diz respeito ao modo como as representações são associadas aos sentidos simbólicos e ideológicos. Ao serem entendidas a partir das dimensões de sua produção e mediação, as representações sociais são estudadas em sua relação com a linguagem (discurso) e seus elementos constitutivos: valores, crenças, imagens, avaliações, posicionamentos. A TRS procura, desse modo, estabelecer um modelo capaz de relacionar os mecanismos psicológicos e sociais da produção de representações com as interações sociais e as formas simbólicas (ideologias).

Como afirma Alves-Mazzoti (2008, p. 35), a abordagem da TRS permite que se faça a integração com outras áreas de conhecimento. Buscamos neste trabalho, por conseguinte, relacionar o estudo da representação segundo a Psicologia Social com abordagens de estudos sociodiscursivos. Não pretendemos seguir a rigor aspectos metodológicos da TRS, já que se trata de uma pesquisa de cunho linguístico-discursivo, mas nos amparamos em tal abordagem para interpretação das representações de docentes em revistas semanais de informação, com foco nos aspectos de natureza social apontados nos trabalhos de Moscovici (1978, 2010).

\section{A CONSTITUIÇÃO DO CORPUS}

O corpus de nossa pesquisa é constituído por artigos, entrevistas e reportagens de duas revistas semanais de informação de grande circulação no Brasil - IstoÉ e Veja. Essas revistas fazem parte do quadro das grandes mídias hegemônicas nacionais e se caracterizam por concentrar grande poder corporativo e econômico, o que lhes permite ampla circulação e amplas possibilidades de captação financeira via publicidade. Concebemos hegemonia em termos de uma rede de poder simbólico construída com base no consenso (GRAMSCI, 1995). Em geral, os consensos produzidos pelas instituições e discursos hegemônicos estão alinhados aos interesses de dominação de grupos específicos. Assim, as mídias hegemônicas se inserem no âmbito das práticas jornalísticas que reproduzem ideologias que servem a interesses globais e particulares das elites simbólicas (VAN DIJK, 2012).

Os gêneros escolhidos podem ser considerados os mais importantes na constituição discursiva das revistas semanais de informação e, portanto, oferecem dados potenciais para a análise das representações sociais docentes. O gênero reportagem é o principal na configuração do núcleo de informação-interpretação da revista, enquanto o artigo de opinião é o gênero que estabelece o núcleo de opinião. Já a entrevista figura entre as ações retóricas de entretenimento e de coluna social das revistas (LIMA, 2013).

Foram selecionados textos que tratam da temática educação no Brasil, de edições de janeiro a novembro de 2016. O quadro a seguir apresenta informações gerais sobre os textos que compõem o corpus:

Fórum linguistic., Florianópolis, v.16,n.2,p.3711-3728, abr./jun. 2019. 


\begin{tabular}{|c|c|c|c|c|c|c|}
\hline & Gênero & Título & Autores/as & Edição & Data & p. \\
\hline \multirow{5}{*}{$\frac{5}{2}$} & R1- Reportagem & Uma revolução no Ensino Médio & $\begin{array}{l}\text { Reportagem não } \\
\text { assinada }\end{array}$ & n. 2442 & $23 / 09 / 16$ & $54-56$ \\
\hline & R2- Reportagem & Eles fazem a cabeça dos jovens & Fabíola Perez & n. 2443 & $30 / 09 / 16$ & $54-56$ \\
\hline & R3 - Reportagem & A falência do ensino público & $\begin{array}{l}\text { Reportagem não } \\
\text { assinada }\end{array}$ & n. 2444 & $07 / 10 / 16$ & $68-71$ \\
\hline & R4 - Reportagem & O colégio dos absurdos & $\begin{array}{l}\text { Reportagem não } \\
\text { assinada }\end{array}$ & n. 2446 & $21 / 10 / 16$ & $44-45$ \\
\hline & E1 - Entrevista & $\begin{array}{l}\text { A desigualdade social é a base da } \\
\text { corrupção }\end{array}$ & Ana Weiss & n. 2428 & $16 / 06 / 16$ & $06-10$ \\
\hline \multirow{9}{*}{$\stackrel{5}{5}$} & A1 - Artigo & Do Magnum .357 p/ Harvard & $\begin{array}{c}\text { Claudio de Moura } \\
\text { Castro }\end{array}$ & n. 2468 & $09 / 03 / 16$ & 32 \\
\hline & A2 - Artigo & O bom rigor do ensino careta & $\begin{array}{c}\text { Claudio de Moura } \\
\text { Castro }\end{array}$ & n. 2484 & $29 / 06 / 16$ & 32 \\
\hline & A3 - Artigo & Impeachment para professores? & $\begin{array}{c}\text { Claudio de Moura } \\
\text { Castro }\end{array}$ & n. 2472 & $06 / 05 / 16$ & 28 \\
\hline & A4 - Artigo & Professor ganha mal? & $\begin{array}{l}\text { Claudio de Moura } \\
\text { Castro }\end{array}$ & n. 2488 & $27 / 07 / 16$ & 29 \\
\hline & R5 - Reportagem & O funil das chances perdidas & Cecília Ritto & n. 2472 & $06 / 04 / 16$ & 78-79 \\
\hline & R6 - Reportagem & Fora do jogo & Maria Clara Vieira & n. 2479 & $25 / 05 / 16$ & 94 \\
\hline & R7- Reportagem & A corrida do ouro & Monica Weinberg & n. 2484 & $29 / 06 / 16$ & $86-87$ \\
\hline & R8 - Reportagem & Bye-bye, velha escola & Cecília Ritto & n. 2502 & $02 / 11 / 16$ & $82-85$ \\
\hline & E2 - Entrevista & O Ensino Médio vai mudar & Monica Weinberg & n. 2488 & $27 / 07 / 16$ & $15-17$ \\
\hline
\end{tabular}

Quadro 2: Informações gerais sobre os textos que compõem o corpus

Fonte: produzido pelos autores

As reportagens da revista IstoÉ foram encontradas nas seções Comportamento, Educação e Brasil, enquanto as reportagens da Veja foram encontradas apenas na seção Educação. As entrevistas pertencem à seção destinada especificamente a esse gênero. No caso da revista Veja, ainda foram selecionados artigos da coluna de Claudio Moura de Castro, pois ele é o articulista da revista que escreve sobre educação, dentre outras temáticas.

\section{ANÁLISE DA REPRESENTAÇÃO SOCIAL DE PROFESSORES/AS}

Como mencionado, a análise da representação de professores/as, neste trabalho, levará em conta categorias do modelo teóricoanalítico de van Leeuwen (1997) proposta para a representação de atores sociais - seguindo as abordagens linguístico-discursivas da ACG, ADC e LSF - e interpretações com base na TRS - segundo a perspectiva de Serge Moscovici. 
Para tanto, começamos pela análise dos textos da revista IstoÉ e, em seguida, passamos para o estudo dos textos da revista Veja. Subdividimos as seções conforme os efeitos potenciais da exclusão e da inclusão dos atores sociais em foco.

\subsection{A REPRESENTAÇÃO DE PROFESSORES/AS EM ISTOÉ}

\subsubsection{Efeitos potenciais da exclusão}

A decisão sobre quais fontes e vozes serão articuladas, bem como a escolha de quais atores sociais serão representados no texto jornalístico, se baseia em valores, crenças e ideologias profissionais que costumam "[...] direcionar o foco e o interesse para vários dos participantes da elite: atores, grupos, classes, instituições, países e regiões [...]” (VAN DIJK, 2012, p. 50). No que se refere à representação social de professores/as, é notável o contraste entre a representação daqueles/as que trabalham no âmbito acadêmico e a dos/as que atuam na educação básica brasileira.

Todos os textos da revista IstoÉ excluem as vozes de docentes da educação básica, e apenas duas reportagens fazem menção a essa categoria profissional. Há, no entanto, outros dois textos - a entrevista "A desigualdade social é a base da corrupção" e a reportagem "Eles fazem a cabeça dos jovens" - que constroem uma representação e identificação favorável a professores universitários específicos.

Além da exclusão desses atores sociais de textos produzidos sobre educação no Brasil, podemos notar, tanto na revista IstoÉ quanto na revista Veja, a exclusão de temas que tratem dos interesses da classe dos/as docentes da educação básica. Essas escolhas, de natureza ideológica, colocam o/a professor/a da educação básica à margem no discurso jornalístico. São, portanto, integrados/as ao rol dos grupos sociais excluídos e silenciados pelas mídias hegemônicas. Eles/as não são usados/as como fontes usuais e confiáveis nos processos de apuração jornalística e produção de notícias e reportagens. Assim, quando são incluídos/as nos textos das mídias hegemônicas, costumam ser representados/as de forma depreciativa (como discutiremos nas subseções seguintes). Esse processo de exclusão discursiva reflete e reforça uma situação de exclusão sociopolítica, a qual mantém o/a professor/a da educação básica na periferia dos processos políticos e das práticas discursivas. Com isso, se constrói a representação de um/a profissional passivo/a e inepto/a, incapaz de analisar e discutir, com propriedade e legitimidade, as condições sociais de seu próprio campo de atuação.

A reportagem "O colégio dos absurdos", ao criticar a presença de diferentes posicionamentos e correntes ideológicas nas atividades do Colégio Pedro II, do Rio de Janeiro, exclui por supressão a representação de professores/as, desconsiderando seus pontos de vista em relação ao que está sendo reportado. Há apenas a voz do reitor da instituição, por ser, nesse caso, considerada pela revista uma autoridade discursiva:

(1) O reitor do colégio, Oscar Halac, divulgou uma nota afirmando que apenas "cedeu o espaço" para a realização do VI Seminário Sobre Capitalismo Burocrático, e que "não havia alunos e nenhum outro servidor do Pedro II presentes” ao evento organizado pelo Grupo de Estudo Leninista-Marxista-Maoísta - Brasil, com apoio de vários outros grupos ligados a universidades. Trata-se de uma meia verdade. Embora fosse um evento fechado, as faixas e cartazes foram expostos durante o período letivo onde a circulação estudantil era livre. (IstoÉ, R4, p. 44).

Ainda assim, a única voz em defesa da instituição é desarticulada e ironizada, o que estrategicamente favorece a legitimação das críticas que estão sendo feitas ao colégio. É importante destacar, ainda, que a representação institucional é construída a partir de escolhas lexicais e avaliações negativas que podem incidir sobre a identificação dos/as docentes e de outros/as servidores/as que trabalham na unidade escolar:

(2) Uma das mais tradicionais escolas do Rio de Janeiro, o Pedro II erra feio ao permitir a pregação da violência e ao contrariar o Estado Democrático de Direito em suas dependências. (IstoÉ, R4, p. 44).

Lexicalizações e expressões específicas, como "erra feio", "pregação da violência”, "contrariar", corroboram uma identificação negativa para a instituição. Por consequência, tal modo de representação institucional contribui para deslegitimar qualquer 
posicionamento, opinião e ação social e política tomada por professores/as, estudantes e outros atores sociais ligados ao colégio. Ao optar por não mencionar ou representar os/as professores/as e seus posicionamentos, a reportagem acaba por desprezar e desqualificar o papel e a importância desses atores sociais na discussão sobre temas que envolvem a educação no país.

\subsubsection{Efeitos potenciais da inclusão}

Como abordamos anteriormente, é possível observar uma nítida assimetria em relação à representação de professores/as universitários/as e docentes da educação básica. Enquanto estes/as são excluídos/as, aqueles/as são representados/as por importantes categorias da personalização: a nomeação, a identificação relacional e a avaliação.

Segundo van Leeuwen (1997), nos jornais e revistas dirigidos à classe média, os/as agentes públicos/as, políticos/as e especialistas tendem a ser referidos/as de modo específico, por meio da individualização (ou assimilação) ou "em termos de sua identidade única, sendo nomeados" (p. 200). É o que podemos observar nos exemplos a seguir:

(3) O filósofo político Michael J. Sandel é conhecido em muitas partes do mundo como o "pop star de Harvard". (IstoÉ, E1, p.06).

(4) Eles têm um desafio complexo: transformar as ideias de Sócrates, Friedrich Nietzsche e William Shakespeare em pílulas de conhecimento para milhões. Essa é a missão que o professor Clóvis de Barros Filho, o historiador Leandro Karnal e o filósofo Mario Sergio Cortella têm cumprido com bom humor e ironia, despertando o interesse de pessoas em todo o País. (IstoÉ, R2, p. 54).

A nomeação e a funcionalização - referência à função e papel profissional - ocorrem de modo recorrente na representação de pessoas públicas, autoridades discursivas, como é o caso da representação que é construída para os professores em foco na entrevista "A desigualdade social é a base da corrupção" e na reportagem "Eles fazem a cabeça dos jovens" (R2).

Segundo a TRS, as ações de nomear e classificar os/as agentes sociais são definidas pelo processo de ancoragem. Como já mencionado, segundo Moscovici (2010), a ancoragem ocorre a partir de nossas vivências, crenças, valores e de nossa interação social. (Re)produzimos as classificações e nomeações necessárias para colocar algo ou alguém como pontos de referência. Sendo assim, a nomeação e funcionalização, bem como outras formas de classificar, tornam os professores/as representados uma referência para o/a leitor/a, segundo os valores e ideologias que fazem parte de suas (inter)ações sociais. Isso, por sua vez, contribui para legitimar a identificação favorável que é construída para esses atores sociais no âmbito educacional.

Outras categorias usadas na construção de representações sociais específicas são a identificação relacional e a avaliação:

(5) Professor da universidade mais antiga e mais famosa dos Estados Unidos desde 1980, [Michael Sandel] formou em seu curso "Justice" nada menos de 15 mil alunos presenciais, além dos incontáveis seguidores das aulas abertas que mantém na internet. (IstoÉ, E1, p. 06).

(6) Professores universitários de formação e intelectuais com respeitável currículo, Clóvis de Barros Filho, Leandro Karnal e Mário Sérgio Cortella se tornaram os maiores pensadores contemporâneos do Brasil, com uma legião de seguidores nas redes sociais e milhões de livros vendidos. (IstoÉ, R2, p. 54).

A identificação relacional diz respeito ao modo como atores sociais são identificados em termos de suas relações pessoais e sociais. Professores/as universitários/as que têm espaço na cobertura da revista são aqueles/as que possuem uma imagem pública e, portanto, são identificados/as pelas suas relações sociais públicas. Como pode ser observado nos excertos (5) e (6), os professores representados são identificados pelo número de alunos/as e seguidores/as na internet, o que reafirma suas interações públicas. 
Além disso, os trechos também exemplificam a representação por avaliação. Enquanto o professor Sandel é avaliado positivamente como "pop star de Harvard" (3) e "professor da antiga e mais famosa universidade dos Estados Unidos" (5), os professores Clóvis de Barros Filho, Leandro Karnal e Mário Sérgio Cortella são representados como "intelectuais com respeitável currículo" e "os maiores pensadores contemporâneos do Brasil" (6).

Enquanto professores/as universitários/as que possuem uma imagem pública têm sua representação construída de modo positivo, específico e individual, professores/as da educação básica são representados/as por meio de referência genérica (generalização), como pode ser observado no exemplo (7):

(7) Repetência, desinteresse, evasão, currículo engessado, professores pouco capacitados. A lista de problemas do Ensino Médio brasileiro, área considerada o grande gargalo da educação atualmente, é longa. (IstoÉ, R1, p. 54).

Essa diferenciação no modo de representar professores/as contribui significativamente para legitimar a assimetria que aí existe. Por um lado, legitima-se uma imagem favorável a docentes acadêmicos/as e, por outro, naturaliza-se o discurso de desqualificação do/a professor/a da rede básica de ensino, conforme construído e reproduzido pelas grandes mídias.

Segundo Jodelet (2001), as representações sociais se apresentam como uma maneira de interpretar e pensar sobre agentes sociais e objetos da realidade cotidiana, uma forma de conhecimento da atividade mental desenvolvida por indivíduos e grupos sociais. Há nas práticas sociais uma preponderante maneira de interpretar e pensar o trabalho docente a partir dos resultados em exames de desempenho. As reportagens de IstoÉ apresentam uma construção discursiva que reproduz essas formas de interpretar as atividades docentes, o que tende a fortalecer representações sociais desfavoráveis ao/à professor/a:

(8) Diferentes problemas levaram a esse desempenho. Um dos mais graves é a falta de especialização e capacitação dos professores. (IstoÉ, R3, p. 69).

(9) Mudar esse cenário exigiria uma aproximação com as universidades e incentivar os estudantes do Ensino Médio a seguir na carreira docente. Somente 2\% dos jovens que se formam no colégio vão para o magistério. O número baixo se dá justamente porque não há nada de atrativo. Pelo contrário: as estruturas são precárias, o ensino é engessado e não há qualquer perspectiva de crescimento. (IstoÉ, R3, p. 69).

(10) É preciso valorizar o educador e investir em uma formação continuada e próxima da realidade das salas de aula. (IstoÉ, R3, p. 69).

Como pode ser observado nos exemplos, por meio da categorização por avaliação, a revista reproduz os discursos sobre a "má formação" e "falta de especialização e capacitação" dos/as docentes da escola básica. Geralmente, esses discursos estão associados à ideia e aos valores que reduzem a educação aos resultados de avaliações de desempenho. Ambas as reportagens - "Uma revolução no Ensino Médio" (R1) e "A falência do Ensino Médio" (R3) - abordam os problemas de desempenho dos/as estudantes em exames como o ENEM. Nesse ínterim, os/as professores/as acabam sendo responsabilizados/as pelo baixo desempenho escolar, justamente por serem avaliados/as como "pouco capacitados".

Nos trechos (9) e (10), podemos observar, ainda, uma construção discursiva descrita por Ferreira (2012, p. 16) como o "movimento de qualificar, desqualificando", ou seja, propõe-se a qualificação do/a professor/a, a partir da formação continuada, apenas depois de ter sido desqualificado/a na representação que é construída no texto.

É importante notar que, apesar de serem representados/as em R1 e R3, os/as professores/as da educação básica são, como em todos os textos analisados, silenciados/as pela revista em relação à temática abordada. As duas reportagens tratam da reforma proposta pelo governo de Michel Temer para o Ensino Médio $^{3}$ e, ambas, passam por um processo de hibridização em que assumem as

${ }^{3}$ Trata-se da Medida Provisória (MP) 746/2016, de 22 de setembro de 2016, que propôs a criação do Novo Ensino Médio. A MP foi aprovada pelo Senado Federal em 08 de fevereiro de 2017 e sancionada pelo presidente da República em 16 de fevereiro de 2017. 
características típicas do gênero reportagem, mas rompem as fronteiras entre o discurso jornalístico e discurso publicitário. Com ações retóricas para além da informação e interpretação, as reportagens tendem a "promover" e "vender" valores e ideias que favorecem o plano de reforma do governo, como representações sobre o baixo desempenho dos/as estudantes do Ensino Médio:

(11) A criação de uma medida provisória para mudar o currículo do Ensino Médio foi a saída encontrada pelo governo federal para tentar aproximar os alunos das escolas, melhorar o aprendizado e prepará-los para o futuro profissional. (IstoÉ, R3, p. 70).

(12) A lista de problemas do Ensino Médio brasileiro, área considerada o grande gargalo da educação atualmente, é longa. [...] Diante do quadro alarmante, o governo brasileiro tomou uma decisão de urgência. Na quinta-feira 22, anunciou uma medida provisória para reformar todo o ciclo de maneira revolucionária. É a maior mudança na educação nacional dos últimos 20 anos, desde a instauração da Lei de Diretrizes e Bases, que norteia o ensino. Além das disciplinas obrigatórias, a ideia é possibilitar ao aluno escolher se aprofundar nas áreas com as quais têm mais afinidade, tornando, assim, o estudo mais atrativo. Há também a preocupação de ampliar o ensino integral. Segundo o presidente Michel Temer, um novo tipo de escola vai surgir a partir desse projeto. (IstoÉ, R1, p. 54).

Entretanto, não há menção alguma sobre os posicionamentos dos/as professores/as em relação à reforma proposta; não há um debate sobre o assunto que envolva todas as partes envolvidas nesse cenário, o que acaba legitimando a marginalização e exclusão dos/as professores/as em discussões sobre a educação no Brasil.

Essas escolhas de exclusão estão relacionadas aos valores e ideologias que orientam a criação e recriação das representações sociais. Desse modo, a revista pode influenciar e mobilizar a opinião pública em relação às representações sociais docentes que circulam nas práticas sociais. Como aponta Alves-Mazzoti (2008), em sua pesquisa sobre a TRS aplicada à educação, as representações sociais são afetadas por fatores ideológicos contraditórios implicados nas práticas cotidianas, o que se aplica bem às construções de sentido voltadas para a representação docente.

\subsection{A REPRESENTAÇÃO SOCIAL DE PROFESSORES/AS EM VEJA}

\subsubsection{Efeitos potenciais da exclusão}

Entre os nove textos da revista Veja, cinco excluem os atores sociais em foco, seja por meio da supressão ou da colocação em segundo plano.

A reportagem "O funil das chances perdidas", que trata do projeto de reforma do Ensino Médio, relega aos/às professores/as um lugar desprivilegiado no que diz respeito à discussão sobre as mudanças propostas para a educação no Brasil, como pode ser observado no único trecho que faz menção a esses atores sociais:

(13) As pressões corporativas também pesam: um sistema em que alunos escolhem matérias sepulta a reserva de mercado, e professores podem ficar sem emprego. 'O currículo tem sido pensado na perspectiva do professor, e não na do jovem', dispara o secretário estadual da Educação do Rio de Janeiro, Antônio Neto. (Veja, R5, p. 79).

Apesar de a discussão sobre as mudanças no Ensino Médio ser de total interesse para o/a professor/a, sua voz e opinião são desconsideradas em toda a reportagem, além de ser representado/a sem importância no debate. A voz do secretário estadual da Educação do Rio de Janeiro, posta como autoridade discursiva, reafirma os sentidos construídos no texto de que, a despeito dos prejuízos que as mudanças propostas podem causar aos/às docentes, seus posicionamentos não são relevantes o suficiente para interferir no assunto. Esse tipo de representação serve para desqualificar potencialmente a atuação e o posicionamento de professores/as frente às mudanças propostas para a educação brasileira. 
As reportagens "Fora do jogo" e "A corrida do ouro", que tratam de questões voltadas para o desempenho escolar, não fazem nenhuma menção à figura do/a professor/a. Nessas reportagens, a educação também é representada na perspectiva do desempenho, como mostra o exemplo a seguir:

(14) Em um cruzamento inédito feito pelo Idados, instituto especializado em analisar os números globais do ensino, os brasileiros que estão no topo da pirâmide escolar tiram notas semelhantes às dos alunos apenas medianos da OCDE (organização que reúne as nações mais ricas). Sim: nossa elite estudantil ombreia com a turma mais ou menos dos países desenvolvidos. (Veja, R6, p. 94).

O texto toma como base os resultados dos/as estudantes brasileiros/as em comparação com os resultados de outros países, sem levar em consideração a realidade do complexo sistema educacional do Brasil. Isso faz com que a figura do/a professor/a seja substituída pelas instituições de ensino e pelos resultados oficiais.

Na entrevista "O Ensino Médio vai mudar", notamos que não há nenhuma pergunta por parte da entrevistadora em relação à docência e à situação dos/as professores/as no que se refere às mudanças propostas para o Ensino Médio - tema da entrevista. Por outro lado, há uma pequena menção do entrevistado, Mendonça Filho, então ministro da Educação, em uma de suas respostas, que coloca o/a professor/a em segundo plano:

(15) [...] sobram no ministério programas onerosos, sem boa gestão nem cobranças de resultados. É dinheiro a fundo perdido. Olhe um exemplo: mais de 800.000 professores estaduais e municipais receberam bolsas com o objetivo de fazer com que as crianças avançassem na alfabetização. Valor total: 2,6 bilhões de reais. E o que aconteceu? Nada. Quase metade dos estudantes ainda chega ao $3^{\circ}$ ano do ensino fundamental fora do nível esperado de alfabetização. (Veja, E2, p. 17).

No caso do trecho (15), podemos observar que o/a professor/a é lembrado/a apenas no sentido negativo, como um exemplo de mau desempenho, o que contribui para a legitimação dos discursos que associam a má qualidade de ensino à atuação do/a professor/a, representando-o/a, assim, de modo depreciativo.

O único texto que suprime a representação de professores/as é o intitulado "O bom rigor do ensino careta”. Neste, o autor defende um argumento favorável ao que chama de "rigor" na educação, no ensino das ciências e das disciplinas básicas. No entanto, não há qualquer menção ao posicionamento de professores/as em relação à forma de ensino argumentada. Nesse caso, o autor do texto toma para si a tarefa de dizer o que é bom para as práticas de ensino no Brasil, sem considerar as vozes e a experiência de quem trabalha diariamente na sala de aula.

Todas essas formas de exclusão revelam a falta de credibilidade na voz e atuação do/a professor/a por parte da revista. A voz desse ator social não é usada como fonte, não é tratada como autoridade discursiva, não é representada como uma voz qualificada e com credibilidade para falar, opinar e se posicionar sobre questões voltadas para a educação no Brasil. Procuram-se as secretarias de Educação, os dados e resultados de avaliações oficiais e internacionais ou professores/as pesquisadores/as de instituições públicas e de referência no país, mas não o/a professor/a da educação básica.

A exclusão é, portanto, uma estratégia relevante para a legitimação das representações negativas e depreciativas construídas para os/as professores/as nas grandes mídias que, em geral, desqualificam sua atuação e voz nas práticas sociais e educacionais. É também potencial para refutar e desprezar os posicionamentos e as opiniões desses atores sociais em questões importantes sobre a educação no país, o que contribui para deslegitimar suas ações e manifestações em prol de melhorias nas condições de trabalho e do sistema educacional. 


\subsubsection{Efeitos potenciais da inclusão}

Em todos os textos que incluem a representação docente na revista, a personalização é a principal estratégia usada para evidenciar as ações e atividades dos atores sociais representados. Usualmente, os/as professores/as são representados/as por funcionalização, pois são referidos/as por sua classe e papel profissional:

(16) Professor, aliás, tem papel bem diferente nesse novo mundo escolar. (Veja, R8, p. 84).

(17) Curiosamente, há uma categoria que se considera acima de qualquer apreciação do seu desempenho: os professores de sistemas públicos. (Veja, A3, p. 28).

(18) Durante os seus 25 anos no ensino, os professores estão sob as regras aparentemente generosas, mas no fundo perversas. (Veja, A4, p. 29).

Como pode ser observado nos trechos (16) e (18), os termos em destaque se referem à classe de professores/as em geral, por meio da referência genérica (generalização). Essa forma de representar é potencial para a universalização e naturalização de identificações específicas para a categoria docente, que faz com que todos/as que pertençam a essa classe profissional sejam associados/as a tais identificações, sejam positivas ou não.

No caso do trecho (17), há a presença da especificação por coletivização, em que os/as professores/as mencionados/as são especificamente os/as que pertencem aos sistemas públicos. Nesse sentido, podemos constatar que a escolha pela representação genérica ou específica depende dos propósitos do texto.

Chamamos novamente a atenção para o contraste que existe entre a representação de professores/as da educação básica e de professores/as pesquisadores/as, principalmente, de referência internacional:

(19) Roland Fryer [...] entrou para a Universidade do Texas, formando-se, em economia, em dois anos e meio. Doutorou-se em três anos e meio na Universidade da Pensilvânia. Hoje é professor em Harvard. O homem é irrequieto e curioso. Com dois economistas da Universidade de Chicago, criou uma escola, para aplicar ideias novas que flutuam por aí. (Veja, A1, p 32).

Como no caso da revista IstoÉ, a representação de professores/as universitários/as é construída em Veja por meio de categorias da personalização, por se tratar de atores sociais tidos como figuras públicas. Pela credibilidade atribuída pela revista ao trabalho desses/as profissionais, sua representação ocorre, em geral, a partir da nomeação e, não apenas da funcionalização, como pode ser observado no excerto (19).

Tal excerto exemplifica as estratégias usadas pela revista no sentido de criar uma representação individual, única e exclusiva para professores/as específicos/as da área acadêmica e, principalmente, de universidades de referência internacional (Harvard). Nesse contraste, ao escolher representar os/as professores/as da educação básica brasileira por meio da generalização, a construção discursiva da revista contribui para legitimar e naturalizar uma identificação negativa para eles/as, desqualificando e menosprezando suas atividades docentes.

$\mathrm{Na}$ reportagem "Bye-bye, velha escola", podemos encontrar outra estratégia relevante referente ao modo de representar professores/as quando a escola e a educação são tratadas como mercadoria, o que pode ser analisado nos exemplos a seguir:

(20) Duas escolas que planejam virar redes, a Concept (em Ribeirão Preto e Salvador) e a Eleva (no Rio de Janeiro), abrem as portas no ano que vem apresentando em seu currículo tudo o que há de mais avançado. (Veja, R8, p. 83).

(21) Com mensalidade média de quase 4.000 reais, [essas escolas] dirigem-se à classe $\mathrm{A}$, interessada em dar aos filhos um ensino forte, integral e menos conservador. (Veja, R8, p. 83). 
(22) A Concept e a Eleva incorporam ao seu método a figura do docente que serve de guia a um determinado número de alunos ao longo de sua vida escolar. Ele conhece seus pontos fracos e fortes, ajuda a montar o currículo, conversa com os pais, está a par dos problemas familiares e os encaminha para uma futura carreira. Enfatiza Parente: "O mestre deixa de ser o detentor do conhecimento para se tornar o arquiteto da aprendizagem. É uma mudança radical de cultura, que exige muito treinamento e outra mentalidade." (Veja, R8, p. 84).

(23) Mesmo com toda sorte de tecnologias disponível, os professores continuam a ser a essência da escola inovadora - a única via possível para a qualidade. (Veja, R8, p. 85).

A reportagem aborda um novo modelo de ensino que está sendo preparado por duas escolas particulares brasileiras com base em modelos internacionais. Como ocorre em IstoÉ, há na reportagem uma mescla entre informação e publicidade - o texto informa sobre o novo modelo proposto pelas escolas e, ao mesmo tempo, "vende", "promove” tal modelo para a "classe A" (21), público alvo da reportagem/revista.

Nesse contexto, os/as professores/as são representados/as a partir da categorização por avaliação:

(24) Na sala de aula moderna, tecnologia é parte ativa do processo e o professor, seu guia no mundo do conhecimento. (Veja, R8, p. 83).

(25) [...] e os professores são "tutores" (mentores em uma jornada personalizada pelo saber). (Veja, R8, p. 83).

(26) Erros conduzirão a mais exercícios e vídeos explicativos; o mestre, por sua vez, identificará melhor as deficiências de cada um. (Veja, R8, p. 84).

(27) A Concept trouxe dois educadores da Finlândia, meca do ensino, para treinar seus professores. (Veja, R8, p. 85).

(28) Mesmo com toda sorte de tecnologias disponível, os professores continuam a ser a essência da escola inovadora - a única via possível para a qualidade. (Veja, R8, p. 85).

Como pode ser observado, os/as professores/as são avaliados/as de modo positivo, por meio de escolhas lexicais que constroem uma identificação favorável em relação ao modelo de ensino que está sendo "vendido" na reportagem. O/a docente, nesse caso, é "mestre" (26), "mentor" (25), "guia" (24), "arquiteto da aprendizagem" (22) e com boa formação, pois está recebendo treinamento de "educadores" (27) de um país que tem os níveis de educação como referência internacional (Finlândia).

Por um lado, esse modo de avaliar promove a valorização do/a profissional docente a partir do desvio de sua função, o que contribui, por outro, para a manutenção de sua desvalorização. Isto é, também podemos observar aqui o "movimento de qualificar, desqualificando" (FERREIRA, 2012, p. 16), conforme observado na análise dos trechos (22) e (23). Nesse caso, propõe-se qualificar o/a professor/a a partir de outras representações profissionais ("guia", "arquiteto"), como se a representação docente não fosse suficientemente favorável, sendo necessário lhe atribuir outras funções. No entanto, essa forma de avaliar tende a reproduzir e reforçar as representações que desqualificam o/a professor/a.

O que podemos apreender sobre esse modo de representar é que, quando a revista e as mídias hegemônicas, em geral, tratam a educação como mercadoria, o/a professor/a é posto/a como um instrumento de operacionalização desse mercado educacional (BRAGA; CAMPOS, 2016) e como o/a responsável pelo alto desempenho da instituição. Essa ideia reforça os discursos naturalizados nas práticas sociais de que a reponsabilidade pelos resultados e desempenho dos/as estudantes é exclusivamente do/a professor/a, sem considerar variáveis socioeconômicas, condições de trabalho, dentre outros aspectos. 
A categorização por avaliação também se destaca nas representações depreciativas construídas nos artigos "Impeachment para professores?" (A3) e "Professor ganha mal?" (A4). Nesses textos, os/as professores/as são representados/as a partir da referência genérica, o que serve de modo potencialmente ideológico para universalizar uma identificação docente particular.

(29) Ou seja, os bons mestres, apontados pelos alunos, tendem a ser os mesmos identificados pela observação feita por profissionais treinados. (Veja, A3, p. 28).

(30) E, na verdade, não há relação clara entre o salário do professor e o que aprendem os alunos. O Amapá tem um dos salários mais altos e piores performances. Minas paga abaixo da média e seus resultados estão entre os melhores. (Veja, A4, p. 29).

(31) E a injustiça dos ótimos ganhando o mesmo que os péssimos. (Veja, A4, p. 29).

A avaliação ocorre a partir de processos atributivos, como ocorre nos exemplos (29) a (31), em que professores/as são categorizados/as a partir da dualidade entre ser "ótimos", ser "bons mestres" e apresentar "resultados que estão entre os melhores" ou ser "péssimos" e ter as "piores performances". Mais uma vez, chamamos a atenção para o fato de que os/as professores/as tendem a ser representados/as apenas em termos de resultados e desempenho:

(32) Não se trata de impeachment, mas de conhecer as forças e fraquezas de cada professor. Sem isso, como ele poderia melhorar o próprio desempenho? (Veja, A3, p. 28).

(33) Essencialmente, há três formas de conhecer o desempenho do professor. (Veja, A3, p. 28).

(34) Ser educador eficaz em sala de aula não traz promoções nem salário. Em contraste, como os professores são estáveis, com completa impunidade, podem ser péssimos a vida toda. (Veja, A4, p. 29).

Nesse sentido, a revista Veja segue a mesma tendência de outras mídias, como já discutido, em relação às escolhas realizadas para a representação docente: a de que o/a professor/a é considerado/a um/a mero/a operacionalizador/a de desempenho e resultados. Esse modo de representar favorece a naturalização e legitimação da ideia de que os resultados da aprendizagem dependem exclusivamente da qualidade do trabalho do/a docente. Por consequência, esse ator social é tido como o único culpado pelos problemas de rendimento escolar, como já afirmamos, sem considerar aspectos socioeconômicos, as condições estruturais das escolas e outros fatores que interferem nos resultados.

A atenção ao trabalho docente tem cada vez mais sido substituída pelos resultados nas avaliações oficiais e internacionais, comparados com os resultados de outros países e instituições, cuja realidade social e econômica se distancia da realidade no Brasil - como ocorre explicitamente na reportagem "Fora do jogo", discutida na subseção anterior.

Em ambos os artigos "Impeachment para professores?" (A3) e "Professor ganha mal?" (A4), pode ser observada a exclusão da voz dos/as professores/as em relação ao que é argumentado. Especialmente no texto "Professor ganha mal?", há uma terminante desvalorização e ridicularização do/a professor/a e de seus direitos, como exemplificamos a seguir:

(35) Durante os seus 25 anos no ensino, os professores estão sob as regras aparentemente generosas, mas no fundo perversas. Os 45 dias de repouso subtraem 37,5 meses. As licenças-prêmio, a cada cinco anos, tiram mais doze meses. Os 25 recessos natalinos reduzem a carreira em 8,3 meses. Dez faltas anuais por saúde somam 8,3 meses. Em comparação com o empreguinho CLT, são seis anos a menos de trabalho, ou seja, os professores trabalham o equivalente a dezenove anos.

Quem fizer mestrado e doutorado poderá sair da aula por 72 meses. Duas gestações rendem doze meses. Quatro candidaturas a vereador dispensam da aula por mais doze meses. Ou seja, quem usar todas as dispensas legais deixará de ensinar por 13,5 anos. Esse seleto grupo trabalha 11, 5 anos na sala de aula e recebe durante 38,5 anos $(13,5+25$ anos). Ótimo para eles, mas quem paga a conta? (Veja, A4, p. 29). 
Não se pode desconsiderar a conjuntura social e política em que esses artigos foram produzidos. No ano de 2016, ao suscitar as propostas do governo de Michel Temer que recaem sobre o Piso Salarial Profissional Nacional e os direitos de aposentadoria, as construções discursivas em A4 se aliam aos interesses do governo, o que revela a aproximação dos posicionamentos da revista com interesses políticos particulares. E, por conseguinte, a voz e os posicionamentos dos/as professores/as são desqualificados e desconsiderados, para manutenção das assimetrias de poder que envolvem esse cenário.

Moscovici (1978) observa que as avaliações que fazem parte da construção das representações sociais se constituem de diferentes universos de opinião segundo classes sociais, culturais e grupos. Em geral, o que fazem as grandes mídias e, mais especificamente, a revista Veja, é apresentar as representações sociais construídas como únicas e universais, sem abrir espaço para os diferentes universos de opinião presentes nas práticas sociais sobre determinados agentes e grupos sociais. É, nesse sentido, que a avaliação positiva ou negativa do/a professor/a na revista pode servir à universalização de representações sociais docentes particulares.

\section{CONSIDERAÇÕES FINAIS}

É comum em narrativas de jornais e da televisão a representação de professores/as em manifestações, greves e outras ações relacionadas a políticas educacionais e salariais. No entanto, na análise que realizamos neste trabalho, observamos que as revistas IstoÉ e Veja fazem escolhas temáticas voltadas para a educação que tendem à exclusão e marginalização do/a professor/a da educação básica e de suas atividades docentes. Por isso, quando são representados/as, são utilizadas estratégias que constroem uma imagem depreciativa e desfavorável a seus posicionamentos e interesses.

Não há nos textos analisados uma preocupação com o papel do/a professor/a na formação humana, cidadã, emancipatória e política. Não são considerados os diversos fatores que influenciam no rendimento escolar quando o/a professor/a é responsabilizado/a pelo mau desempenho dos/as estudantes. As vozes e os posicionamentos dos/as docentes do ensino básico são totalmente excluídos e sua representação está subordinada, por vezes, à lógica do mercado educacional.

Nesse sentido, as representações sociais docentes construídas nas revistas se resumem em ideias e discursos que identificam o/a professor/a da educação básica como despreparado/a, ultrapassado/a e não capacitado/a; por sua "má formação", não é considerado/a como especialista, nem fonte confiável; é representado/a como mero/a operacionalizador/a de desempenho escolar e, portanto, o/a único/a responsável pela má qualidade de ensino. Essas formas de representar contribuem significativamente para legitimar e naturalizar as assimetrias e desigualdades que envolvem a profissão docente.

Como afirma Moscovici (2010), as representações sociais são "teorias" sobre o real, baseadas em valores, crenças e ideologias. Ao tratá-las desta forma, como construções da realidade social, as grandes mídias se tornam meios potenciais de criar um consenso favorável aos discursos e ideologias que (re)produzem uma identificação e representação negativa para o/a professor/a da escola básica, contribuindo para a manutenção de relações de dominação.

\section{REFERÊNCIAS}

ALVES-MAZZOTI, A. J. Representações sociais: aspectos teóricos e aplicações à educação. Revista Múltiplas Leituras, v. 1, n. 1, p. 18-43, jan./jun. 2008.

ALVES-MAZZOTI, A. J. Representações da identidade docente: uma contribuição para a formulação de políticas. Pesquisa em síntese, Rio de Janeiro, v. 15, n. 57, p. 579-594, out./dez. 2007. 
BONINI, A. Análise crítica de gêneros jornalísticos. In: SPB JOR - ENCONTRO NACIONAL DE PESQUISADORES EM JORNALISMO, 10., nov. 2012, Curitiba: Pontifícia Universidade Católica do Paraná. Anais eletrônicos. Disponível em: https://goo.gl/jNWzpr. Acesso em: 17 out. 2017.

BRAGA, C.F.; CAMPOS, P. H. F. Representações sociais e comunicação: a imagem social do professor na mídia e seus reflexos na (re) significação identitária. Goiânia: Editora Kelps, 2016.

FAIRCLOUGH, N. Analyzing discourse: textual analysis for social research. London: Routledge, 2003.

FAIRCLOUGH, N. Discurso e mudança social. Coord. trad. revisão e prefácio à ed. brasileira I. Magalhães. Brasília: Editora Universidade de Brasília, 2001.

FERREIRA, K. Z. Quando o professor é notícia? Imagens de professor e imagens do jornalismo. 197 f. Tese (doutorado) Universidade de São Paulo, Faculdade de Educação, Programa de Pós-Graduação em Educação, São Paulo, 2012. Disponível em: https://goo.gl/K5FPsp. Acesso em: 17 out. 2017.

GRAMSCI, A. A concepção dialética da história. Rio de janeiro: Civilização Brasileira, 1995.

JODELET, D. Representações Sociais: um domínio em expansão. In: (org.). As Representações Sociais. Tradução Lílian Ulup. Rio de Janeiro: Editora da UERJ, 2001.p. 17- 44.

LAWN, M. Os professores e a fabricação de identidades. Currículo sem Fronteiras, v. 1, n. 2, p. 117-130, jul./dez. 2001.

LEITE, M. A. Discursos, identidades e representações sobre a imagem docente. Cadernos CESPUC, Belo Horizonte, n. 23 , p. $137-$ $149,2013$.

LIMA, S. C. Hipergênero: agrupamento ordenado de gêneros na constituição de um macroenunciado. 278 f. Tese (doutorado) Universidade de Brasília, Programa de Pós-Graduação em Linguística, Brasília, 2013. Disponível em: https://goo.gl/zyReUF. Acesso em: 17 out. 2017.

MOSCOVICI, S. A representação social da psicanálise. Trad. Álvaro Cabral. Rio de Janeiro: Zahar Editores, 1978[1961].

MOSCOVICI, S. Representações sociais: investigações em psicologia social. 7. ed. Petrópolis: Vozes, 2010.

RAMALHO, V.; RESENDE, V. M. Análise de discurso (para a) crítica: o texto como material de pesquisa. Campinas: Pontes, 2011.

THOMPSON, J. B. Ideologia e cultura moderna: teoria social crítica na era dos meios de comunicação de massa. 9. ed. Petrópolis: Vozes, 2011.

VAN DIJK, T. A. Discurso e poder. Trad. Judith Hoffnagel, Karina Falcone (org.). 2. ed. São Paulo: Contexto, 2012.

VAN LEEUWEN, T. A representação de atores sociais. In: PEDRO, E. R. (org.). Análise Crítica do Discurso: uma perspectiva sociopolítica e funcional. Lisboa: Caminho, 1997. p. 169-222.

\section{(๑) $\circledast \circledast$}

